\title{
Detection of Trichomonas vaginalis antigen in women by enzyme immunoassay
}

\author{
A YUlE, ${ }^{*}$ M C A GELlAN, $\dagger$ J D ORIEL, $\dagger$ J P ACKERS,* \\ From the Department of *Medical Protozoology, London School of Hygiene and Tropical Medicine, and the \\ Department of $†$ Genitourinary Medicine, University College Hospital, London
}

SUMMARY An enzyme immunoassay (EIA) was developed for the detection of Trichomonas vaginalis antigen in vaginal swabs. Four hundred and eighty two women attending a sexually trans- : mitted disease (STD) clinic were tested; $44(9 \cdot 1 \%)$ were positive by culture, $32(6 \cdot 6 \%)$ were positive $r$ by wet film examination, and $54(11 \cdot 2 \%)$ were considered to be positive for trichomonal antigen by EIA. Taking culture as the reference method, the EIA had a sensitivity of $93.2 \%$ and a specificity 응 of $97 \cdot 5 \%$. The predictive value of a positive test was $82 \%$ and that of a negative test was $99 \cdot 3 \%$.

Despite the widespread use of metronidazole and related chemotherapeutic agents, the incidence of Trichomonas vaginalis infection in England and Wales has remained constant over the past decade. ${ }^{1}$ This has been partly due to the lack of an effective diagnostic test for this sexually transmitted protozoan parasite. Wet film microscopy misses $20-30 \%$ of those cases detected by culture methods ${ }^{2}$; results of cultures are not available for at least 48 hours and the advantage of initiating treatment on the patient's first visit is lost. Serodiagnostic tests have not attained the specificity and sensitivity required for clinical use. ${ }^{3}$ We developed an enzyme immunoassay (EIA) for the detection of $T$ vaginalis antigen and evaluated its performance with vaginal swabs taken from 482 women attending a sexually transmitted disease clinic. The assay is of the tandem type and uses the same affinity isolated polyclonal antibody fraction as both capture antibody and biotinylated indicator antibody.

\section{Patients and methods}

Four hundred and eighty two female outpatients attending the department of genito-urinary medicine (University College Hospital, London) were tested. Vaginal material for wet film microscopy, $T$ vaginalis culture, and EIA was collected on cotton swabs. Culture swabs were inoculated into $10 \mathrm{ml}$ modified Diamond's trypticase, yeast extract, maltose (TYM) medium $^{4}$ supplemented with $10 \%$ horse serum, $1000 \mathrm{U} / \mathrm{ml}$ penicillin, $0 \cdot 25 \mathrm{mg} / \mathrm{ml}$ streptomycin, and $0.025 \mathrm{mg} / \mathrm{ml}$ amphotericin B. Swabs taken for antigen detection by EIA were broken off into $1 \mathrm{ml}$ phosphate buffered saline (PBS) containing $0.05 \%(\mathrm{v} / \mathrm{v})$ Tween 20 and $0.05 \%(w / v)$ sodium azide (PBS-Tween 20) and stored at $4^{\circ} \mathrm{C}$. Samples were assayed within 24 hours of collection or stored at $-20^{\circ} \mathrm{C}$ for later testing. Culture tubes were examined microscopically for motile parasites after two and six days of incubation at $37^{\circ} \mathrm{C}$.

PREPARATION OF TRICHOMONAL ANTIGEN $T$ vaginalis isolates LUMP 1910 and LUMP 1042 used for rabbit immunisation were cultured in Meyer's HSP-1 medium ${ }^{5}$ supplemented with $15 \%$ rabbit serum, $1000 \mathrm{U} / \mathrm{ml}$ penicillin, and $0.25 \mathrm{mg} / \mathrm{ml}$ streptomycin. Isolates 1910 and 1911 (used for solu- $\frac{7}{O}$ ble antigen and Nonidet P40 lysate preparation) were cultured in Diamond's trypticase, yeast extract, malt- o ose (TYM) medium. Organisms were washed three times with PBS before use or storage at $-20^{\circ} \mathrm{C}$. Pel- $N$ leted trichomonads $\left(5 \times 10^{7}\right.$ cells) were resuspended in $3 \mathrm{ml} \mathrm{PBS}$, frozen at $-20^{\circ} \mathrm{C}$, and thawed at $4^{\circ} \mathrm{C}$; the process was repeated to give three freeze-thaw cycles. After centrifugation $\left(2000 \times g\right.$ for 15 minutes at $\left.4^{\circ} \mathrm{C}\right) \stackrel{\mathbb{D}}{\mathbb{D}}$ the soluble antigen fraction was assayed for protein content ${ }^{6}$ and stored at $-20^{\circ} \mathrm{C}$.

ANTITRICHOMONAS ANTISERUM

Two New Zealand white rabbits were immunised intramuscularly with $2 \times 10^{6}$ organisms (comprising 
equal numbers of isolates 1910 and 1042) in Freund's Complete Adjuvant and boosted on days 14 and 28 with the same dose in Incomplete Adjuvant. Blood was collected on day 35 .

AFFINITY ISOLATION OF SPECIFIC ANTIBODY Trichomonal protein was extracted by lysis with the non-ionic detergent Nonidet P40 (NP40, BDH 56009). A $1 \mathrm{ml}$ pellet of washed $T$ vaginalis isolate $1911\left(10^{8}\right.$ cells $)$ was resuspended in $5 \mathrm{ml}$ lysis medium: $0.02 \mathrm{M}$ Tris-hydrochloric acid, $0.15 \mathrm{M}$ sodium chloride $(\mathrm{pH} 8.0)$, containing $0.5 \%$ NP40 (v/v), $0.001 \mathrm{M}$ phenylmethylsulphonyl fluoride (Sigma P7626), $0.001 \mathrm{M}$ iodoacetamide (Sigma 1-6125), and $10 \mathrm{mg} / \mathrm{l}$ $\mathrm{N} \alpha$-p-tosyl-L-lysine chloromethyl ketone (Sigma $\mathrm{T}-7254)$. After 15 minutes of incubation at $0^{\circ} \mathrm{C}$ the mixture was centrifuged at $2000 \times g$ for 15 minutes at $4^{\circ} \mathrm{C}$, the supernatant dialysed against $2 \times 11$ changes of $0 \cdot 1 \mathrm{M}$ sodium carbonate, $0 \cdot 15 \mathrm{M}$ sodium chloride

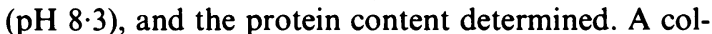
umn of NP40 lysate protein coupled to cyanogen bromide activated Sepharose 4B (Pharmacia) was prepared according to the manufacturer's instructions using $6 \mathrm{mg}$ protein $/ \mathrm{ml}$ gel. A $5 \mathrm{ml}$ aliquot of pooled immune rabbit serum was applied to an equal volume of coupled gel, the column washed extensively with PBS, and bound antibody eluted with $0.1 \mathrm{M}$ glycinehydrochloric acid ( $\mathrm{pH} 2 \cdot 8$ ). The $\mathrm{pH}$ of eluted fractions was immediately adjusted to 7.8 by collection into $1 \mathrm{M}$ Tris $(0.2 \mathrm{ml} / 5 \mathrm{ml}$ fraction). Fractions containing antibody were pooled and dialysed against $0.1 \mathrm{M}$ sodium hydrogen carbonate $(\mathrm{pH} 9.0)$ before concentration to $0.5-1 \mathrm{mg} / \mathrm{ml}$ by ultrafiltration to yield anti- $T$ vaginalis immunoglobulin (ATV-Ig).

\section{BIOTINYLATION OF ATV-IG}

$\mathrm{N}$-hydroxysuccinamido-biotin (Sigma H-1759) was dissolved at $5 \mathrm{mg} / \mathrm{ml}$ in dimethyl sulphoxide (BDH 56009) and added to ATV-Ig in the ratio of 1:1 (by weight). After four hours of incubation at room temperature the mixture was dialysed against.PBS before aliquots of $0.1 \mathrm{ml}$ were taken and stored at $-20^{\circ} \mathrm{C}$.

\section{AVIDIN-ALKALINE PHOSPHATASE (AV-ALP) CONJUGATE}

Avidin (Sigma A-9275) was conjugated to alkaline phosphatase (Sigma P-6774) by a modified glutaraldehyde procedure. ${ }^{7}$ An avidin:enzyme ratio of 1:2 (by weight) was used.

\section{EIA PROCEDURE}

Microtitre plate (NUNC Immuno II) wells were coated with $0.1 \mathrm{ml} \mathrm{ATV-Ig}(5 \mathrm{ug} / \mathrm{ml}$ in $0.05 \mathrm{M}$ carbonate-bicarbonate buffer, $\mathrm{pH} 9 \cdot 8$ ) overnight at $4^{\circ} \mathrm{C}$ and stored at the same temperature; antibody coated plates had a minimum shelf life of two weeks.
All subsequent incubations were at room temperature. Plates were washed four times with distilled water containing $0.05 \%$ Tween 20 (DW-Tween 20) just before use. Sample tubes were vortex mixed, the swab discarded, and $0.1 \mathrm{ml}$ added to triplicate wells. After two hours of incubation in a moist box plates were washed five times with DW-Tween 20 and $0.1 \mathrm{ml}$ biotinylated ATV-Ig $(5 \mu \mathrm{g} / \mathrm{ml}$ in PBS-Tween 20 containing $1 \%$ rabbit serum) added to each well. Plates were incubated for one hour before being washed five times with DW-Tween 20 . A $0 \cdot 1 \mathrm{ml}$ volume of Av-ALP (1/1500 in PBS-Tween 20 containing $0.5 \%, w / v$, bovine serum albumin, Sigma A-7906) was added to each well and the plates reincubated for 30 minutes. After again washing five times with DW-Tween 20 colour was developed by the addition of $0.1 \mathrm{ml}$ p-nitrophenol phosphate substrate solution to each well (Sigma $104-105,1 \mathrm{mg} / \mathrm{ml}$ in $0.05 \mathrm{M}$ carbonate-bicarbonate buffer containing $0.002 \mathrm{M}$ magnesium chloride, $\mathrm{pH} 9 \cdot 8$ ). The reaction was terminated after 30 minutes by the addition of $0.05 \mathrm{ml}$ 0.02M L-cysteine (Sigma C-7755) to each well. Optical density was measured at $405 \mathrm{~nm}$ using a Dynatech MR 600 microplate reader.

\section{Results}

Of the specimens from 482 women tested, $44(9 \cdot 1 \%)$ were positive for $T$ vaginalis on culture; $32(6.6 \%)$ of these were also positive on wet film examination. Culture results were used to select an appropriate cut off point for the EIA. Two controls were included on each plate: a negative control in which PBS-Tween 20 was substituted for the test sample, and a positive control consisting of soluble trichomonal antigen at $100 \mathrm{ng} / \mathrm{ml}$ in PBS-Tween 20. A sample was considered to be positive if the mean test optical density was greater than or equal to the mean optical density of the $100 \mathrm{ng} / \mathrm{ml}$ positive control after subtraction of the mean negative control optical density value from both. An additional $500 \mathrm{ng}$ soluble antigen $/ \mathrm{ml}$ control provided a readily visible marker of assay performance.

Using the above definition, 41 of 44 with positive results on culture were also considered to be positive by EIA ( $8.5 \%$ of the total number tested); a further nine samples were positive by EIA but negative on culture. Antigen was not detected by EIA in samples from three women who were negative on culture after two days of incubation but became positive on culture after six days. Taking culture as the reference method, the EIA had a sensitivity of $93.2 \%$ and a specificity of $97.5 \%$. The predictive value of a positive test was $82 \%$, and the predictive value of a negative test was $\mathbf{9 9 \cdot 3 \%}$. 


\section{Discussion}

This preliminary study indicates that the EIA is highly specific; 431 culture negative and EIA negative samples gave uniformly low background optical density values with no apparent interference by normal or pathological vaginal flora or in the presence of red blood cells, degraded epithelial cells, or large numbers of leucocytes. The clinical histories of nine women giving false positive EIA results showed that at the time of sampling five women had vaginal symptoms suggestive of $T$ vaginalis infection, while four women were asymptomatic.

The optical density values obtained with false positive samples were comparable with those obtained with several samples positive on culture and indicated the presence of antigen at concentrations equivalent to $100-1000 \mathrm{ng}$ soluble trichomonal antigen fraction $/ \mathrm{ml}$. This suggests the possibility of culture failure in at least some of these cases and illustrates the problem of selecting a suitable reference method when assessing diagnostic tests for infectious agents.

A second possible cause is the difference in the quantity of vaginal material obtained when separate swabs are taken for culture and antigen detection; the order of collection was not stipulated for the purpose of this study. This may have contributed to the failure of EIA to detect trichomonal antigen in three samples which were negative on culture after two days but positive after six days of incubation, suggesting the presence of only small numbers of organisms (and therefore low antigen titres) in these patients. One of these isolates was compared with a number of isolates from samples giving high optical density values in the EIA for its ability to inhibit the binding of a predetermined quantity of the polyclonal anti- $T$ vaginalis serum to soluble trichomonal antigen; no noticeable differences were found, indicating that EIA failure was not due to antigenic heterogeneity between isolates.

Most of the samples positive on culture gave high optical density values ( $>1.0$ units) and could be detected visually within minutes of the addition of substrate. This indicates that considerable quantities of antigen (equivalent to 5-10 $\mu \mathrm{g}$ soluble antigen fraction $/ \mathrm{ml}$ ) are present in the vagina during $T$ vaginalis infection, and makes the prospect of a rapid immunodiagnostic test which would combine the sensitivity of culture with the speed and simplicity of wet film examination a realistic one. We are at present examining the feasibility of such a test using high affinity monoclonal antibodies in a two site simultaneous assay.

We thank the medical and nursing staff of the department of genitourinary medicine, University College Hospital, for their help. This study was supported by the Medical Research Council.

\section{References}

1 Anonymous. Sexually transmitted diseases: extract from the annual report of the Chief Medical Officer of the Department of Health and Social Security for the year 1983. Genitourin Med 1985;61:204-7.

2 Ackers JP, Lumsden WHR, Catterall RD, Coyle R. Antitrichomonal antibody in the vaginal secretions of women infected with Trichomonas vaginalis. British Journal of Venereal Diseases 1975;51:319-23.

3 Street DA, Taylor-Robinson D, Ackers JP, Hanna NF, McMillan A. Evaluation of an enzyme-linked immunosorbent assay for the detection of antibody to Trichomonas vaginalis. British Journal of Venereal Diseases 1982;58:330-3.

4 Diamond LS. The establishment of various trichomonads of animals and man in axenic culture. $J$ Parasitol 1957;43:488-90.

5 Meyer EA. Giardia lamblia: isolation and axenic cultivation. Exp Parasitol 1976;39:101-5.

6 Bradford MN. A rapid and sensitive method for the quantitation of microgram quantities of protein utilising the principle of protein-dye binding. Anal Biochem 1976;72:248-54.

7 Bessos H, Yule A. Direct comparisons between a radio-immune antiglobulin test, an enzyme-linked antiglobulin test, and a haemagglutination assay: application to the screening of antiRBC sera and monoclonal antibodies. Vox Sang 1983; 44:289-95.

Requests for reprints to: Dr JP Ackers, Department of Medical Protozoology, London School of Hygiene and Tropical Medicine, Keppel Street, London WCIE 7HT, England. 